\title{
Carta aberta em favor da criação de programas de asma no Brasil (CAPA)
}

\author{
Brazilian political proposal for asthma programs on primary health care
}

\author{
Alcindo Cerci Neto, Mauro Musa Zamboni, Márcia Alcântara Holanda
}

0 fórum de discussão de programas de asma conseguiu reunir diversas entidades representativas de pacientes, gestores em saúde e especialistas, em 02 de novembro de 2006, durante o XXXIII Congresso Brasileiro de Pneumologia e Tisiologia, em Fortaleza, para discutir e propor sugestões a fim de aprimorar as ações nacionais que vêm sendo realizadas em programas de asma.

Atualmente, é fundamental o estímulo à criação de programas de asma no Brasil. lsso se deve às condições favoráveis de financiamento, à exigência crescente da população, aos índices de morbidade e mortalidade encontrados, à necessidade de melhoria de qualidade de vida desses pacientes, e à instituição do tratamento correto e atual desta doença, com base em critérios de gravidade e, também, incorporando conceitos atuais de controle da doença.

A descentralização, municipalização e regionalização dos programas são fundamentais para melhorar seu funcionamento. Já existem no Brasil iniciativas bem-sucedidas, embora sejam pontuais e isoladas. A solução para as grandes dificuldades encontradas pelos programas já existentes esbarra na falta de apoio dos gestores, principalmente no que tange a recursos humanos qualificados, dificuldades na capacitação e conscientização dos profissionais de saúde, garantia de regularidade no fornecimento de medicamentos adequados, e estabelecimento de um sistema de referência e contra-referência, integrando os vários níveis de atenção envolvidos.

0 processo de convencimento e sensibilização dos profissionais e gestores quanto à importância da estruturação do atendimento ao asmático nos municípios pode ser fundamentado em alguns aspetos:

a) Os gestores devem ser alertados sobre os dados epidemiológicos da doença, tais como morbidade, mortalidade, sobrecarga das malhas de cuidados, e custos crescentes envolvidos com a doença e fármaco-economia;

b) A existência de programas de asma que já demonstram efetividade em alcançar a melhoria de tais indicadores, com resultados extremamente favoráveis para a população, sistema de saúde, profissionais e pacientes; e c) A asma deve sempre ser tratada em conjunto com a rinite alérgica, de forma a obter melhores resultados.

Para que haja a implantação e o funcionamento regular de um programa de asma, uma equipe multiprofissional deve ser criada, a qual será encarregada de planejar, acompanhar e avaliar os programas. Essa equipe poderia ser composta por um médico pneumologista e/ou alergista, médico de família, enfermeira e gestor. Na ausência de um especialista de referência no município, um médico que não tenha essas especialidades, mas que seja capacitado no tratamento de asma, poderia se tornar a referência. Dependendo do município, sua disponibilidade e viabilidade, quaisquer outros profissionais podem ser agregados ou mesmo coordenar a equipe de planejamento, tais como pediatras, farmacêuticos, auxiliares de enfermagem, fisioterapeutas, agentes comunitários, entre outros. Torna-se, assim, indispensável que essa equipe mínima de planejamento, acompanhamento e avaliação, tenha uma carga horária mínima, para realizar essas funções da melhor maneira possível. Os agentes comunitários de saúde e a estratégia de saúde da família são fundamentais para o funcionamento de qualquer programa de asma, devendo sua participação ser estimulada por meio da capacitação, conscientização e educação em asma.

De suma importância para qualquer iniciativa nesta área é o processo de capacitação dos profissionais da rede de saúde. Existem diferentes encaminhamentos para esta atividade, a depender da estrutura do município, dos recursos humanos disponíveis e do modelo de saúde existente. Fazse necessário apenas que exista uma carga horária mínima teórica (mínimo de $4 \mathrm{~h}$ ) e prática (mínimo de $2 \mathrm{~h}$ ). A metodologia da capacitação poderá ser realizada através de:

1. Treinamento teórico conjunto dos profissionais (médicos, enfermeiros, etc.), e treinamento prático realizado em serviço, ou seja, nas próprias unidades de saúde; ou de

2. Treinamento teórico direcionado para cada categoria profissional em centro de referência, e treinamento prático conjunto em centro de referência. 
Os asmáticos que não têm total conhecimento do quadro que os aflige poderiam ser captados para os programas de diversas maneiras: em salas de emergência, hospitais, busca ativa na comunidade por intermédio do agente comunitário de saúde, ambulatórios médicos públicos ou privados, ambulatórios de medicina do trabalho nas empresas, nas escolas públicas ou privadas por meio de palestras, nas aulas de educação física (com envolvimento dos professores), em farmácias e, por fim, através da mídia. 0 controle social e a participação da comunidade, tanto na elaboração das diretrizes como no acompanhamento dos programas, são fundamentais e devem ser estimulados. Além disso, deve haver uma conscientização destes grupos quanto ao empoderamento de seu tratamento, estimulando-os a exigir que as metas de financiamento e custeio do tratamento de sua doença sejam exigidas das autoridades competentes. Uma das maneiras é a criação de Associações de Pacientes Asmáticos Locais.

A questão do financiamento dos programas é fundamental. Apesar de já existirem enormes avanços nesta área, por meio das portarias ministeriais 2.084 e 2.577 , há a necessidade de ampliar e garantir a continuidade dos recursos financeiros já previstos e o aprimoramento destas portarias. As propostas de alteração das portarias citadas são:

a) Apoio técnico e científico, a fim de dar maior autonomia aos municípios e estados na aquisição de medicamentos específicos pactuados localmente, e não apenas daqueles recomendados pela portaria 2084;

b) Pressão das entidades representativas signatárias deste documento para que se aumentem os recursos para a asma, através da aprovação da PEC 29; e

c) Melhor divulgação junto aos municípios com referência aos recursos financeiros existentes.
Mais uma vez, os programas de asma já existentes há mais de dois anos, e com experiências exitosas, podem servir de modelo e inspiração na implantação de outros programas, sob o prisma da regionalização. Para que isso aconteça, se faz necessária uma maior exposição dos programas já existentes, na forma de eventos realizados por órgãos governamentais, como CONASEMs e Ministério da Saúde, congressos e fóruns regionais e nacionais promovidos pelas sociedades de especialidades médicas envolvidas neste processo, ONGs, ou por meio de todas as formas de imprensa.

Como agenda, instituir um grupo de trabalho interinstitucional para dar encaminhamento a esta carta, de forma propositiva e deliberativa, bem como gerar um grupo de capacitação nacional para estimular a criação de programas de asma.

\section{Alcindo Cerci Neto}

Pneumologista. Mestre em Medicina pela Universidade Estadual de Londrina; Coordenador Médico ASMS.

Coordenador do II Fórum Nacional de Programas de Asma

Mauro Musa Zamboni Pneumologista do INCA/MS -

Rio de Janeiro. Mestre em Pneumologia pela Universidade Federal Fluminense. Vice Presidente da ALAT

Márcia Alcântara Holanda

Mestrado em saúde pública. Membro da

Comissão de Asma da SCPT. Coordenadora do Programa de Asma de Fortaleza PROAICA. Coordenadora do I GFCA 